\title{
Radiation Overdose
}

National Cancer Institute

\section{Source}

National Cancer Institute. Radiation Overdose. NCI Thesaurus. Code C50862.

A higher than intended cumulative dose of radiation to a single field. 